\title{
A White-Light-Emitting Small Molecule: Synthesis, Crystal Structure, and Optical Properties
}

\author{
Sin-Kai Fang, Hsing-Yang Tsai, Jiun-Wei Hu, and Kew-Yu Chen \\ Department of Chemical Engineering, Feng Chia University, 40724 Taichung, Taiwan \\ Correspondence should be addressed to Kew-Yu Chen; kyuchen@fcu.edu.tw
}

Received 21 December 2013; Accepted 30 January 2014; Published 26 May 2014

Academic Editor: David Lee Phillips

Copyright (C) 2014 Sin-Kai Fang et al. This is an open access article distributed under the Creative Commons Attribution License, which permits unrestricted use, distribution, and reproduction in any medium, provided the original work is properly cited.

\begin{abstract}
A white-light-emitting small molecule (1) was synthesized and characterized by single-crystal X-ray diffraction. Compound 1 undergoes an excited-state intramolecular proton transfer (ESIPT) reaction, resulting in a tautomer that is in equilibrium with the normal species and exhibiting a dual emission that covers almost all of the visible spectrum, and consequently generates white light. Furthermore, the geometric structures, the frontier molecular orbitals (MOs), and the potential energy curves for 1 in the ground and the first singlet excited state were fully rationalized by density functional theory (DFT) and time-dependent DFT calculations. The results show that the forward ESIPT and backward ESIPT may happen on the same timescale, enabling the excited-state equilibrium to be established.
\end{abstract}

\section{Introduction}

Organic fluorescent molecules with excited-state intramolecular proton transfer (ESIPT) characteristics have been constantly drawing significant attention due to their peculiar optical properties [1-6]. An ESIPT reaction commonly involves the transfer of a hydroxyl (amino) proton to an acceptor such as imine nitrogen (carbonyl oxygen) through a preexisting hydrogen bonding configuration [7-9]. As shown in Figure 1, molecules that exhibit ESIPT in the ground state exist predominantly as enol (E) forms; however, upon photoexcitation, they undergo tautomerization into keto forms $\left(\mathrm{E}^{*} \rightarrow \mathrm{K}^{*}\right.$ ) via an ultrafast and irreversible ESIPT process occurring in the subpicosecond time domain [10]. The resulting proton-transfer tautomer is substantially different in structure and electronic configuration from its corresponding ground state, that is, a large Stokes shifted $\mathrm{K}^{*} \rightarrow \mathrm{K}$ emission. This unusual optical property has many practical applications, typical examples of which are probes for solvation dynamics [11, 12] and biological environments [13, 14], photochromic materials [15], fluorescence microscopy imaging [16], chemosensors [17-20], nearinfrared fluorescent dyes [21], nonlinear optical materials [22], and organic light emitting diodes (OLEDs) [23-25].

Attempts at exploiting single-molecule-based whitelight-emitting ESIPT chromophores as the white lighting materials have recently been an important issue of research, since the use of a single molecule can provide easy fabrication with perfect color reproducibility and stability [26, 27]. In 2009, Park and coworkers synthesized and characterized, for the first time, a white-light-emitting single molecule dyad, consisting of two noninteracting chromophores showing ESIPT [28]. Later in 2011, we paved a new and feasible avenue en route to white light generation based on a single ESIPT system [29]. Taking advantage of an adiabatic ESIPT reaction, we were able to show that broad blue emission from the excited starting material and broad red emission from an ESIPT molecule 2 (Scheme 1) combined to generate white light as if there were two molecules present in the sample. However, due to its relatively low overall fluorescence quantum yield, the electroluminescent performance using 2 as an active layer is only decent compared with the work mentioned early utilizing multi-ESIPT moieties [28, 30]. To expand the scope of the 2-based chromophores available for designing systems for high performance single-moleculebased white-light-emitting OLEDs, the present research reports the synthesis of a new derivative of 2 with a tert-butyl moiety attached to the naphthalene ring, that is, 8-tertbutyl-1-hydroxy-11H-benzo[b]fluoren-11-one (1). Its X-ray structure, as well as optical and electrochemical properties, and complementary time-dependent density functional theory (TD-DFT) calculations are also studied. 


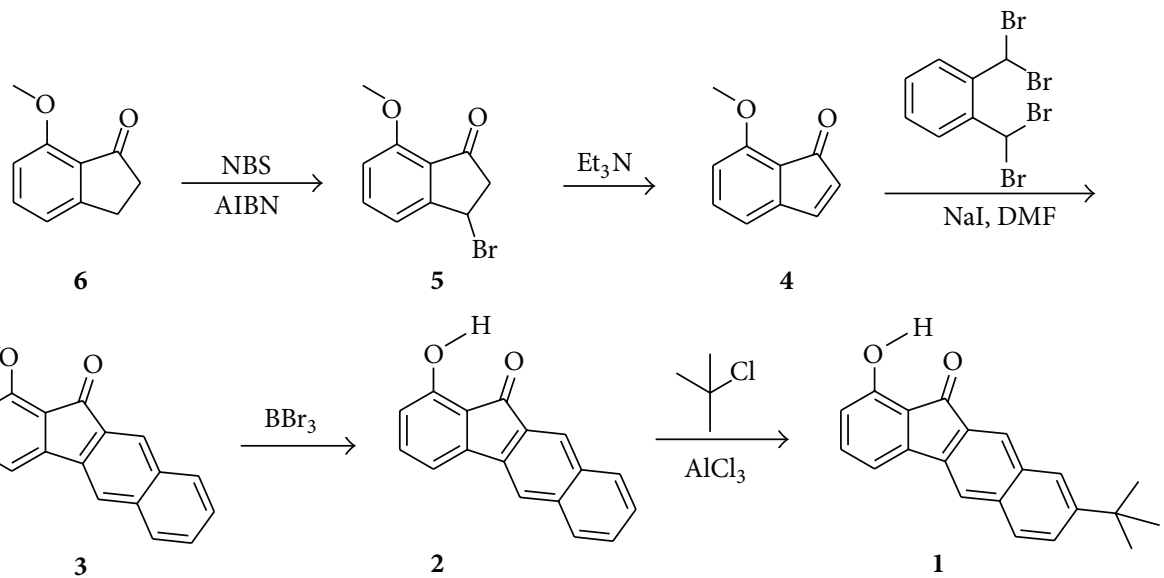

SCHEme 1: The synthetic route of $\mathbf{1}$.

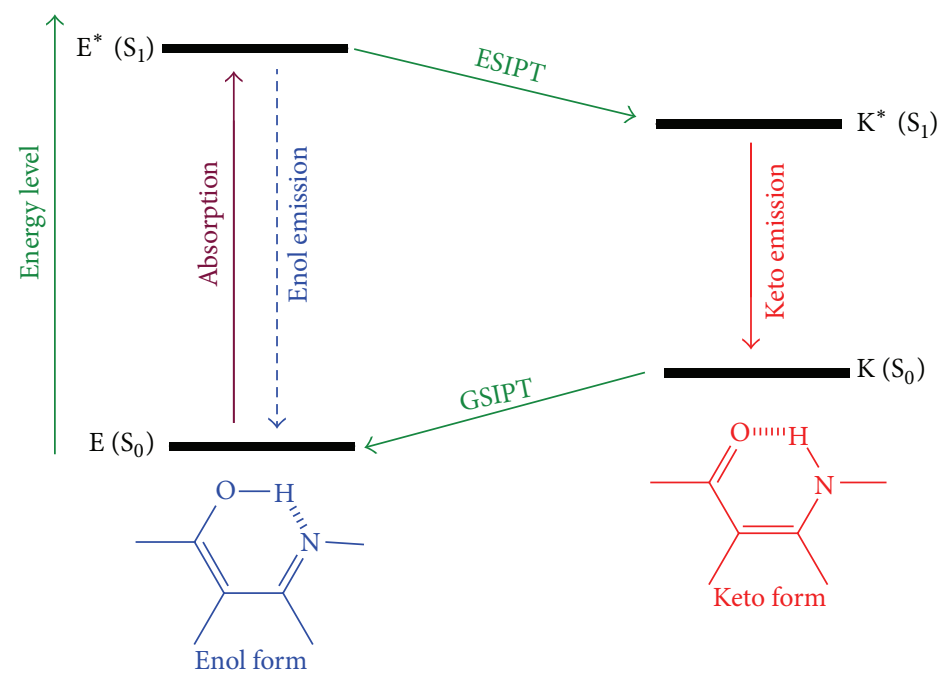

FIGURE 1: Characteristic four-level photocycle scheme of the ESIPT process.

\section{Experimental}

2.1. Chemicals and Instruments. The starting materials such as 7-methoxy-2,3-dihydro- $1 \mathrm{H}$-inden-1-one (6), $\mathrm{N}$-bromosuccinimide (NBS), 2,2' -azobisisobutyronitrile (AIBN), triethylamine, $\alpha, \alpha, \alpha^{\prime} \alpha^{\prime}$-tetrabromo-o-xylene, sodium iodide, boron tribromide, tert-butyl chloride, and aluminum trichloride were purchased from Merck, ACROS, and SigmaAldrich. Solvents were distilled freshly according to standard procedure. Column chromatography was performed using silica gel Merck Kieselgel si 60 (40-63 mesh).

${ }^{1} \mathrm{H}$ NMR spectra were recorded in $\mathrm{CDCl}_{3}$ on a Bruker $400 \mathrm{MHz}$ spectrometer. Mass spectra were recorded on a VG70-250S mass spectrometer. The absorption and emission spectra were measured using a Jasco V-570 UV-Vis spectrophotometer and a Hitachi F-4500 fluorescence spectrophotometer, respectively. The single-crystal X-ray diffraction data were collected on a Bruker Smart 1000 CCD area-detector diffractometer. The redox potentials were measured using cyclic voltammetry on a CHI 620 analyzer.
The data were collected and analyzed using electrochemical analysis software. All measurements were carried out in dichloromethane containing $0.1 \mathrm{M}$ tetrabutylammonium hexafluorophosphate $\left(\mathrm{TBAPF}_{6}\right)$ as the supporting electrolyte under ambient conditions after purging for $15 \mathrm{~min}$ with $\mathrm{N}_{2}$. The conventional three-electrode configuration was employed, which consisted of a glassy-carbon working electrode, a platinum counter electrode, and a $\mathrm{Ag} / \mathrm{AgNO}_{3}(0.1 \mathrm{M})$ reference electrode calibrated with ferrocene/ferrocenium $\left(\mathrm{Fc} / \mathrm{Fc}^{+}\right)$as an internal reference.

\subsection{Synthesis and Characterization}

2.2.1. Synthesis of 3-Bromo-7-methoxy-2,3-dihydro-1H-inden1-one (5). 7-Methoxy-2,3-dihydro- $1 H$-inden-1-one $(1.0 \mathrm{~g}$, $6.2 \mathrm{mmol}$ ) and $\mathrm{N}$-bromosuccinimide $(1.2 \mathrm{~g}, 6.8 \mathrm{mmol})$ were dissolved in $20 \mathrm{~mL}$ of $\mathrm{CCl}_{4}$ and $12 \mathrm{mg}$ ( $1 \mathrm{~mol} \%$ ) of $2,2^{\prime}$ azobisisobutyronitrile (AIBN) was added. The mixture was slowly stirred and heated to $80^{\circ} \mathrm{C}$ for 2 hours. After cooling, the mixture was poured into cold water, extracted with 
$\mathrm{CH}_{2} \mathrm{Cl}_{2}$, and dried with anhydrous $\mathrm{MgSO}_{4}$. After the solvent was removed, the crude product was purified by silica gel column chromatography with eluent ethyl acetate/ $n$-hexane $(1 / 4)$ to afford $5(1.1 \mathrm{~g}, 74 \%) .{ }^{1} \mathrm{H}$ NMR $\left(\mathrm{CDCl}_{3}, \mathrm{ppm}\right) 7.62(\mathrm{t}$, $J=8.5 \mathrm{~Hz}, 1 \mathrm{H}), 7.20(\mathrm{~d}, J=8.0 \mathrm{~Hz}, 1 \mathrm{H}), 6.87(\mathrm{~d}, J=8.5 \mathrm{~Hz}$, $1 \mathrm{H}), 5.52\left(\mathrm{dd}, J_{1}=7.0 \mathrm{~Hz}, J_{2}=2.0 \mathrm{~Hz}, 1 \mathrm{H}\right), 3.92(\mathrm{~s}, 3 \mathrm{H}), 3.32$ $\left(\mathrm{dd}, J_{1}=18.5 \mathrm{~Hz}, J_{2}=7.0 \mathrm{~Hz}, 1 \mathrm{H}\right), 2.97\left(\mathrm{dd}, J_{1}=18.5 \mathrm{~Hz}, J_{2}=\right.$ $2.0 \mathrm{~Hz}, 1 \mathrm{H})$; MS (FAB) $m / z 240(\mathrm{M}+\mathrm{H})^{+}$. HRMS calcd. for $\mathrm{C}_{10} \mathrm{H}_{10} \mathrm{BrO}_{2} 240.9864$, found 240.9866 .

2.2.2. Synthesis of 7-Methoxy-1H-inden-1-one (4). 3-Bromo7-methoxy-2,3-dihydro- $1 \mathrm{H}$-inden-1-one $(1.0 \mathrm{~g}, 4.1 \mathrm{mmol})$ in $\mathrm{CCl}_{4}$ was cooled in an ice bath, and $1.93 \mathrm{~mL}(1.4 \mathrm{~g}, 14.0 \mathrm{mmol})$ of triethylamine was added slowly. The reaction mixture was allowed to warm to room temperature and stir overnight. After the solvent was removed, the crude product was purified by silica gel column chromatography with eluent ethyl acetate $/ n$-hexane $(1 / 4)$ to afford $4(0.63 \mathrm{~g}, 95 \%) .{ }^{1} \mathrm{H}$ $\operatorname{NMR}\left(\mathrm{CDCl}_{3}, \mathrm{ppm}\right) 7.42(\mathrm{~d}, J=6.0 \mathrm{~Hz}, 1 \mathrm{H}), 7.34(\mathrm{t}, J=8.0 \mathrm{~Hz}$, $1 \mathrm{H}), 6.85(\mathrm{~d}, J=8.8 \mathrm{~Hz}, 1 \mathrm{H}), 6.70(\mathrm{~d}, J=8.0 \mathrm{~Hz}, 1 \mathrm{H}), 5.84(\mathrm{~d}, J$ $=6.0 \mathrm{~Hz}, 1 \mathrm{H}), 3.95(\mathrm{~s}, 3 \mathrm{H}) ;{ }^{13} \mathrm{C} \mathrm{NMR}\left(100 \mathrm{MHz}, \mathrm{CDCl}_{3}, \mathrm{ppm}\right)$ $196.57,156.50,147.38,147.03,144.48,136.02,127.70,115.65$, 114.67, 55.89; MS (FAB) $m / z 161(\mathrm{M}+\mathrm{H})^{+}$. HRMS calcd. for $\mathrm{C}_{10} \mathrm{H}_{9} \mathrm{O}_{2}$ 161.0603, found 161.0608 .

2.2.3. Synthesis of 7-Methoxy-1H-inden-1-one (3). A mixture of solution of $\alpha, \alpha, \alpha^{\prime} \alpha^{\prime}$-tetrabromo- $o$-xylene ( $\left.1.3 \mathrm{~g}, 3.1 \mathrm{mmol}\right)$, 7-methoxy- $1 \mathrm{H}$-inden-1-one $(0.5 \mathrm{~g}, 3.1 \mathrm{mmol})$, sodium iodide $(1.8 \mathrm{~g}, 12 \mathrm{mmol})$, and dry DMF $(30 \mathrm{~mL})$ was stirred at $65^{\circ} \mathrm{C}$ for 24 hours. The reaction mixture was poured into cold water $(70 \mathrm{~mL})$ containing sodium bisulfite $(1.0 \mathrm{~g})$. The yellow precipitate was purified by silica gel column chromatography with eluent ethyl acetate $/ n$-hexane $(1 / 4)$ to afford $3(0.73 \mathrm{~g}$, 90\%). ${ }^{1} \mathrm{H} \mathrm{NMR}\left(\mathrm{CDCl}_{3}, \mathrm{ppm}\right) 8.14(\mathrm{~s}, 1 \mathrm{H}), 7.79 \sim 7.88(\mathrm{~m}$, $3 \mathrm{H}), 7.43 \sim 7.54(\mathrm{~m}, 3 \mathrm{H}), 7.31(\mathrm{~d}, J=7.6 \mathrm{~Hz}, 1 \mathrm{H}), 6.85(\mathrm{~d}, J=$ $8.4 \mathrm{~Hz}, 1 \mathrm{H}), 3.99$ (s, 3H); ${ }^{13} \mathrm{C} \mathrm{NMR}\left(100 \mathrm{MHz}, \mathrm{CDCl}_{3}, \mathrm{ppm}\right)$ $191.06,158.54,146.83,137.56,136.96,136.50,133.76,133.10$, $130.58,128.68,128.59,126.78,125.01,122.74,119.03,113.26$, $112.37,55.89$; MS (FAB) $m / z 261(\mathrm{M}+\mathrm{H})^{+}$. HRMS calcd. for $\mathrm{C}_{18} \mathrm{H}_{13} \mathrm{O}_{2}$ 261.0916, found 261.0918.

2.2.4. Synthesis of 1-Hydroxy-11H-benzo[b]fluoren-11-one (2). 1-Methoxy-11H-benzo[b]fluoren-11-one (300 mg, $1.1 \mathrm{mmol}$ ) was dissolved in $10 \mathrm{~mL}$ of dichloromethane in a $50 \mathrm{~mL}$ roundbottom flask, and the flask was placed in an ice bath at $0^{\circ} \mathrm{C}$. A solution of boron tribromide $(0.25 \mathrm{~mL}, 1.0 \mathrm{M}$ solution in dichloromethane) was added carefully to the stirred solution under a nitrogen atmosphere. After 4 hours, the reaction was cooled and the reaction mixture was then hydrolyzed by carefully shaking it with $10 \mathrm{~mL}$ of water and extracted twice with $10 \mathrm{~mL}$ of dichloromethane. The combined organic phases were then dried over magnesium sulfate, filtered, and evaporated in vacuo; the crude product was purified by silica gel column chromatography with eluent ethyl acetate/ $n$ hexane (1/10) to afford $2(269 \mathrm{mg}, 95 \%) .{ }^{1} \mathrm{H} \mathrm{NMR}\left(\mathrm{CDCl}_{3}\right.$, ppm) $8.64(\mathrm{~s}, 1 \mathrm{H}), 8.07(\mathrm{~s}, 1 \mathrm{H}), 7.84(\mathrm{~d}, J=7.5 \mathrm{~Hz}, 1 \mathrm{H}), 7.78(\mathrm{~s}$, $1 \mathrm{H}), 7.77(\mathrm{~d}, J=9.0 \mathrm{~Hz}, 1 \mathrm{H}), 7.54(\mathrm{t}, J=7.5 \mathrm{~Hz}, 1 \mathrm{H}), 7.38 \sim 7.46$ $(\mathrm{m}, 2 \mathrm{H}), 7.15(\mathrm{~d}, J=7.0 \mathrm{~Hz}, 1 \mathrm{H}), 6.76(\mathrm{~d}, J=8.0 \mathrm{~Hz}, 1 \mathrm{H}) ;{ }^{13} \mathrm{C}$
NMR (100 MHz, $\left.\mathrm{CDCl}_{3}, \mathrm{ppm}\right)$ 195.51, 157.66, 144.25, 137.99, $137.81,136.74,133.41,132.68,130.78,129.13,128.85,127.08$, $125.54,120.16,120.01,117.40,113.00$; MS (FAB) $m / z 247(\mathrm{M}+$ $\mathrm{H})^{+}$. HRMS calcd. for $\mathrm{C}_{17} \mathrm{H}_{11} \mathrm{O}_{2}$ 247.0759, found 247.0755.

2.2.5. Synthesis of 8-tert-Butyl-1-hydroxy-11H-benzo[b]fluoren-11-one (1). 1-Hydroxy-11H-benzo[b] fluoren-11-one $(200 \mathrm{mg}$, $0.8 \mathrm{mmol}$ ) was added to tert-butyl chloride $(5 \mathrm{~mL})$. The flask was kept at $0^{\circ} \mathrm{C}$ with an ice bath and all inlets were protected by drying tubes. Anhydrous aluminum chloride $(280 \mathrm{mg}$, $2.1 \mathrm{mmol}$ ) was added dropwise over $1 \mathrm{~h}$ and the mixture was allowed to stir for another hour. $\mathrm{H}_{2} \mathrm{O}(20 \mathrm{~mL})$ was added to the flask and the mixture was allowed to stir for $10 \mathrm{~min}$. The mixture was extracted with dichloromethane and dried with magnesium sulfate; the crude product was purified by silica gel column chromatography with eluent ethyl acetate/ $n$ hexane (1/8) to afford 1 (208 mg, 85\%). Yellow parallelepipedshaped crystals suitable for the crystallographic studies reported here were isolated over a period of six weeks by slow evaporation from a dichloromethane solution. ${ }^{1} \mathrm{H}$ NMR $\left(\mathrm{CDCl}_{3}, \mathrm{ppm}\right) 8.68(\mathrm{~s}, 1 \mathrm{H}), 8.11(\mathrm{~s}, 1 \mathrm{H}), 7.81(\mathrm{~s}, 2 \mathrm{H}), 7.77(\mathrm{~d}, J=$ $8.0 \mathrm{~Hz}, 1 \mathrm{H}), 7.64(\mathrm{~d}, J=8.0 \mathrm{~Hz}, 1 \mathrm{H}), 7.43(\mathrm{t}, J=8.0 \mathrm{~Hz}, 1 \mathrm{H}), 7.18$ $(\mathrm{d}, J=8.0 \mathrm{~Hz}, 1 \mathrm{H}), 6.77(\mathrm{~d}, J=8.0 \mathrm{~Hz}, 1 \mathrm{H}), 1.40(\mathrm{~s}, 9 \mathrm{H}) ;{ }^{13} \mathrm{C}$ $\mathrm{NMR}\left(100 \mathrm{MHz}, \mathrm{CDCl}_{3}, \mathrm{ppm}\right)$ 195.7, 157.7, 150.2, 144.5, 137.7, $137.6,134.9,133.5,132.7,128.6,128.0,126.2,125.7,120.2$, 119.6, 117.2, 112.9, 34.9, 31.1; MS (FAB) $m / z 303(\mathrm{M}+\mathrm{H})^{+}$. HRMS calcd. for $\mathrm{C}_{21} \mathrm{H}_{19} \mathrm{O}_{2}$ 303.1385, found 303.1389.

2.2.6. Crystal Structural Determination. A single crystal of 1 with dimensions of $0.41 \mathrm{~mm} \times 0.39 \mathrm{~mm} \times 0.10 \mathrm{~mm}$ was selected. The lattice constants and diffraction intensities were measured with a Bruker Smart 1000 CCD area detector radiation $(\lambda=0.71073 \AA)$ at $297(2) \mathrm{K}$. An $\omega-2 \theta$ scan mode was used for data collection in the range of $2.38 \leqq$ $\theta \leqq 26.36^{\circ}$. A total of 19859 reflections were collected and 3158 were independent $\left(R_{\text {int }}=0.0320\right)$, of which 2455 were considered to be observed with $I>2 \sigma(I)$ and used in the succeeding refinement. The structure was solved by direct methods with SHELXS-97 [31] and refined on $F^{2}$ by full-matrix least-squares procedure with Bruker SHELXL97 packing [32]. All nonhydrogen atoms were refined with anisotropic thermal parameters. The hydrogen atoms refined with riding model position parameters isotropically were located from difference Fourier map and added theoretically. At the final cycle of refinement, $R=0.0488$ and $w R=$ $0.1163\left(w=1 /\left[\sigma^{2}\left(F_{o}^{2}\right)+(0.0551 P)^{2}+0.6249 P\right]\right.$, where $P=$ $\left.\left(F_{o}^{2}+2 F_{c}^{2}\right) / 3\right), S=1.028,(\Delta / \sigma)_{\max }=0.002,(\Delta / \rho)_{\max }=0.162$, and $(\Delta / \rho)_{\min }=-0.191 \mathrm{e} / \AA^{3}$.

2.3. Computational Methods. The Gaussian 03 program was used to perform the $a b$ initio calculation on the molecular structure [33]. Full geometry optimizations of compound 1 were carried out with the $6-31 G^{* *}$ basis set to the B3LYP functional. The hybrid DFT functional B3LYP has proven to be a suitable DFT functional to describe hydrogen bond [34]. Vibrational frequencies were also performed to check whether the optimized geometrical structures for $\mathbf{1}$ were 
at energy minima, transition states, or higher order saddle points. After obtaining the converged geometries, the TDB3LYP/6-31G ** was used to calculate the vertical excitation energies. Emission energies were obtained from TDDFT/B3LYP/6-31G ${ }^{* *}$ calculations performed on $S_{1}$ optimized geometries. The phenomenon of photoinduced proton transfer (PT) reaction in $\mathbf{1}$ can be most critically addressed and assessed by evaluating the potential energy curve (PEC) for the PT reaction. For the $\mathrm{S}_{0}$ state all of the other degrees of freedom are relaxed without imposing any symmetry constraints. The excited-state $\left(\mathrm{S}_{1}\right)$ PEC for the ESIPT reaction in $\mathbf{1}$ has been constructed on the basis of TD-DFT optimization method.

\section{Results and Discussion}

3.1. Synthesis and Characterization. Scheme 1 shows the chemical structure and the synthetic route of 1 . The synthesis of 1 started from a conventional bromination of 7-methoxy2,3-dihydro- $1 H$-inden-1-one (6), followed by the elimination of the bromo adduct (5), giving a reactive dienophile 4 . The naphthalene moiety can then be fused onto the $\mathrm{C}(2)-$ $\mathrm{C}(3)$ double bond by placing 4 through a reaction with $\alpha, \alpha, \alpha^{\prime} \alpha^{\prime}$-tetrabromo-o-xylene [29], yielding 3. Subsequently, compound 3 was subjected to the deprotection with $\mathrm{BBr}_{3}$ to give 2. Finally, the fried-craft alkylation at the 8-position of $\mathbf{2}$ was carried out by the reaction of $\mathbf{2}$ with tert-butyl chloride and aluminum trichloride, giving $\mathbf{1}$ with an overall product yield of $51 \%$. The presence of a single tert-butyl substituent of 1 can be verified by the presence of a signal at $\delta 1.40 \mathrm{ppm}$ $(9 \mathrm{H})$ and eight signals at $\delta 6.7-8.1 \mathrm{ppm}(8 \mathrm{H})$ in the ${ }^{1} \mathrm{H}$ NMR spectrum.

3.2. Hydrogen Bond Studies. The dominance of an enolnormal form for 1, namely, the intramolecular hydrogenbond formation between $\mathrm{O}(1)-\mathrm{H}$ and $\mathrm{O}(2)$, is firmly supported by a combination of ${ }^{1} \mathrm{H}$ NMR and X-ray singlecrystal analyses (Figure 2). In the ${ }^{1} \mathrm{H}$ NMR studies, the existence of an intramolecular hydrogen bond between $\mathrm{O}(1)-$ $\mathrm{H}$ and $\mathrm{O}(2)$ is evidenced by the observation of a substantial downfield shift of the proton peak at $8.68 \mathrm{ppm}$ (in $\mathrm{CDCl}_{3}$ ). The hydrogen bonding energy $(\Delta E$ in $\mathrm{kcal} / \mathrm{mol}$ ) can be empirically calculated by introducing Schaefer's correlation [35], expressed as $\Delta \delta=(-0.4 \pm 0.2)+\Delta E$, where $\Delta \delta$ is given in parts per million for the difference between chemical shift in the $\mathrm{O}-\mathrm{H}$ peak of 1 and that in phenol $(\delta$ 4.29). Accordingly, the hydrogen-bonding energy is calculated to be $4.79 \pm 0.2 \mathrm{kcal} / \mathrm{mol}$ and is in good agreement with the theoretical calculations $(6.27 \mathrm{kcal} / \mathrm{mol})$. Note that compound 1 has a weaker intramolecular hydrogen bond than most other ESIPT molecules $[36,37]$, which may account for its unique dual emission feature (vide infra).

3.3. X-Ray Structures. The structure of $\mathbf{1}$ was further confirmed by single-crystal X-ray diffraction analysis. Compound 1 crystallizes in the monoclinic space group $P 2_{1} / c$, with $a=15.7248(9), b=6.0166(3), c=17.5500(8) \AA, \alpha=$ $90^{\circ}, \beta=110.515(2)^{\circ}$, and $\gamma=90^{\circ}$. As shown in Figure 2 , the
TABLE 1: Comparison of the experimental and optimized geometric parameters of 1 .

\begin{tabular}{|c|c|c|}
\hline & X-ray & DFT \\
\hline \multicolumn{3}{|l|}{ Bond lengths $(\AA)$} \\
\hline $\mathrm{C}(1)-\mathrm{O}(1)$ & $1.357(2)$ & 1.348 \\
\hline $\mathrm{C}(7)-\mathrm{O}(2)$ & $1.222(2)$ & 1.233 \\
\hline $\mathrm{C}(1)-\mathrm{C}(2)$ & $1.390(3)$ & 1.407 \\
\hline$C(3)-C(4)$ & $1.396(3)$ & 1.409 \\
\hline $\mathrm{C}(4)-\mathrm{C}(5)$ & $1.376(2)$ & 1.387 \\
\hline$C(5)-C(6)$ & $1.399(2)$ & 1.409 \\
\hline $\mathrm{C}(7)-\mathrm{C}(8)$ & $1.495(2)$ & 1.492 \\
\hline $\mathrm{C}(9)-\mathrm{C}(10)$ & $1.361(2)$ & 1.370 \\
\hline $\mathrm{C}(11)-\mathrm{C}(12)$ & $1.426(2)$ & 1.433 \\
\hline $\mathrm{C}(15)-\mathrm{C}(16)$ & $1.419(2)$ & 1.423 \\
\hline $\mathrm{C}(18)-\mathrm{C}(19)$ & $1.538(3)$ & 1.539 \\
\hline \multicolumn{3}{|l|}{ Bond angles $\left({ }^{\circ}\right)$} \\
\hline $\mathrm{O}(1)-\mathrm{C}(1)-\mathrm{C}(6)$ & $121.7(2)$ & 121.3 \\
\hline$C(6)-C(1)-C(2)$ & $118.1(2)$ & 117.8 \\
\hline$C(4)-C(5)-C(6)$ & $120.3(2)$ & 119.6 \\
\hline $\mathrm{C}(7)-\mathrm{C}(8)-\mathrm{C}(9)$ & $108.1(2)$ & 108.3 \\
\hline $\mathrm{C}(10)-\mathrm{C}(11)-\mathrm{C}(12)$ & $119.9(2)$ & 120.1 \\
\hline$C(14)-C(15)-C(16)$ & $117.0(2)$ & 117.2 \\
\hline $\mathrm{C}(10)-\mathrm{C}(11)-\mathrm{C}(17)$ & $122.3(2)$ & 122.1 \\
\hline $\mathrm{C}(15)-\mathrm{C}(18)-\mathrm{C}(19)$ & $111.5(2)$ & 109.4 \\
\hline \multicolumn{3}{|l|}{ Torsion angles $\left({ }^{\circ}\right)$} \\
\hline $\mathrm{O}(1)-\mathrm{C}(1)-\mathrm{C}(2)-\mathrm{C}(3)$ & $-178.8(2)$ & -179.9 \\
\hline $\mathrm{C}(3)-\mathrm{C}(4)-\mathrm{C}(5)-\mathrm{C}(9)$ & $179.6(2)$ & 179.9 \\
\hline$C(6)-C(5)-C(9)-C(10)$ & $179.1(2)$ & 179.9 \\
\hline $\mathrm{C}(17)-\mathrm{C}(11)-\mathrm{C}(12)-\mathrm{C}(13)$ & $-178.2(2)$ & -179.9 \\
\hline
\end{tabular}

molecular structure of $\mathbf{1}$ is nearly planar (except for tert-butyl group), which is also confirmed by geometry optimization in our DFT calculation (Table 1 and Figure 4). This, together with $2.919 \AA$ of $\mathrm{O}(1)-\mathrm{O}(2)$ distance, supports the existence of a six-membered-ring intramolecular hydrogen bond. Additionally, the longer $\mathrm{O}(1)-\mathrm{O}(2)$ distance in $\mathbf{1}$ than that $(\mathrm{O}(1)-$ $\mathrm{O}(2)<2.7 \AA$ ) in most other ESIPT molecules [36, 37] supports that compound $\mathbf{1}$ has a weaker intramolecular hydrogen bond. This is possible due to the fact that the carbonyl oxygen $\mathrm{O}(2)$ locates at the five-membered-ring cyclopenta2,4-dienone moiety (Figure 2 ), such that the $\angle \mathrm{O}(1)-\mathrm{H}-\mathrm{O}(2)$ angle is expected to be deviated from $120^{\circ}$, a perfect sixmember-ring hydrogen bonding formation. This viewpoint is confirmed by the $\angle \mathrm{O}(1)-\mathrm{H}-\mathrm{O}(2)$ angle of $144.8^{\circ}$, according to the X-ray structure analysis. Careful examination of the crystal structure also indicates that there is no substantial $\pi-\pi$ stacking between the tetracyclic plane and its adjacent one. Thus, we can ascertain that the tert-butyl group not only largely increases the solubility of $\mathbf{1}$ compared with $\mathbf{2}$ but also reduces intermolecular contact and aggregation.

3.4. Photophysical Properties. Figure 3 reveals the steady state absorption and emission spectra of $\mathbf{1}$ in cyclohexane, and pertinent photophysical data is given in Table 2. Compound 


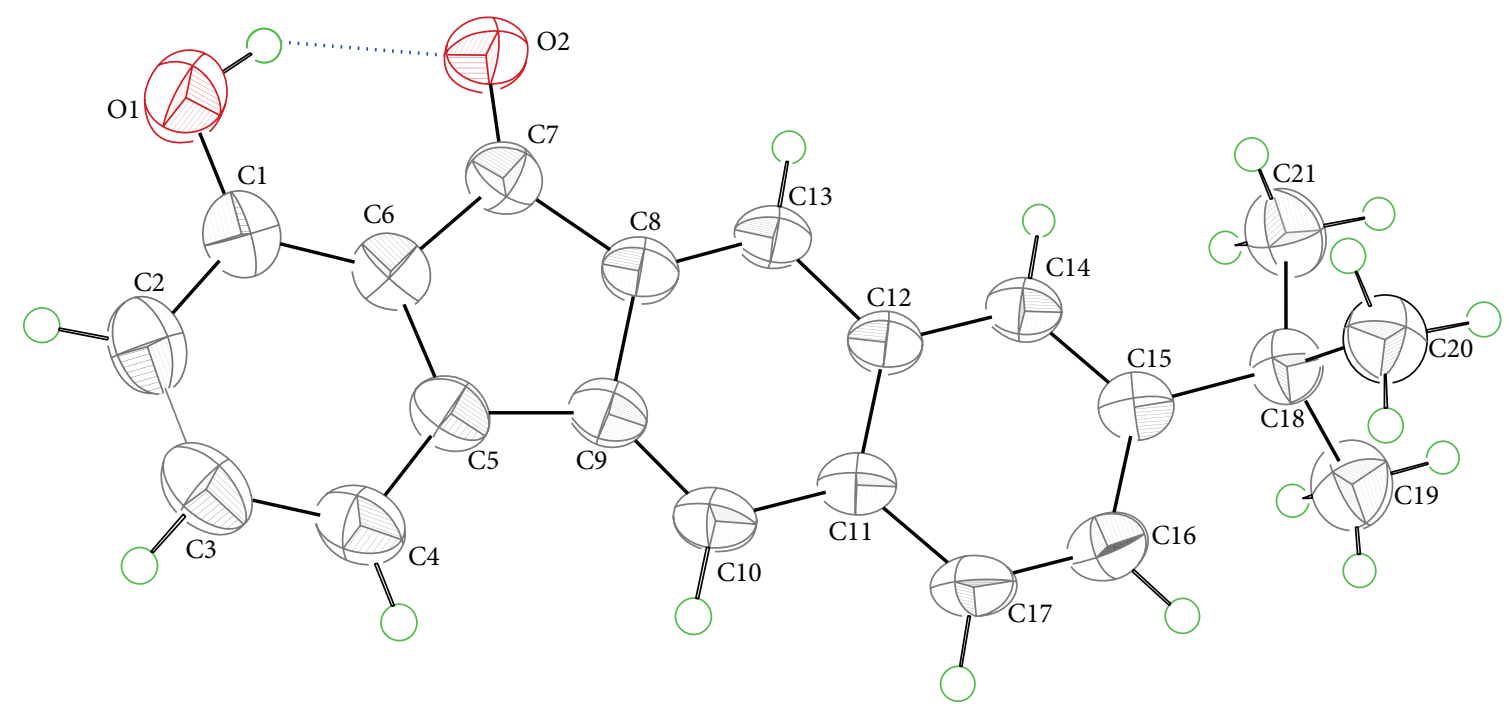

FIGURE 2: Displacement ellipsoid representation of 1 with the labelling scheme. The ellipsoids are drawn at the $50 \%$ probability level and the $\mathrm{H}$ atoms are drawn as spheres of arbitrary radii. The blue dashed line denotes the intramolecular hydrogen bond.

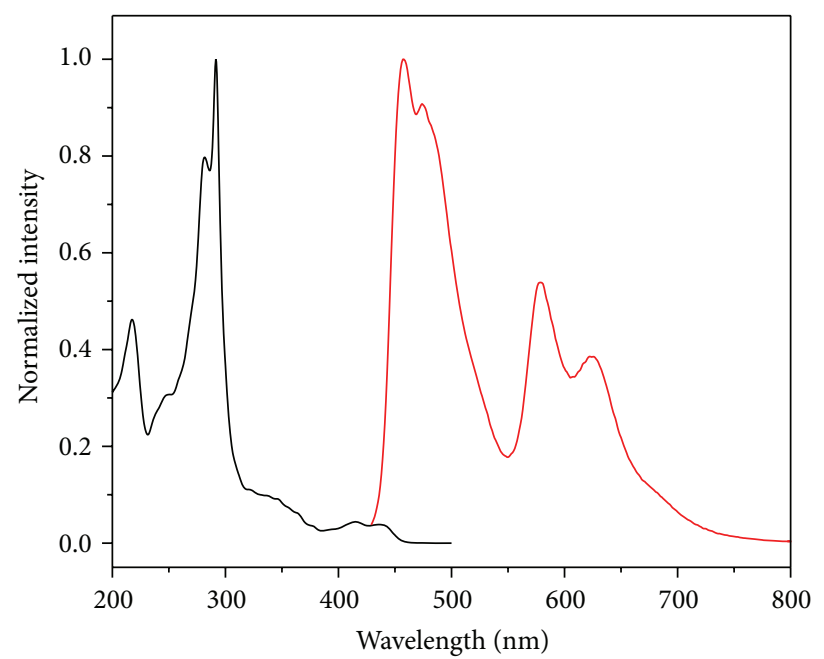

FIgURE 3: Normalized absorption (black line) and emission (red line) spectra of $\mathbf{1}$ in cyclohexane.

1 exhibits the lowest lying absorption band maximized at $430 \mathrm{~nm}$ with vibronic structures, attributed to a $\pi \rightarrow \pi^{*}$ transition, which is also supported by the calculated frontier orbitals shown in Figure 5. In addition, the absorption spectrum of $\mathbf{1}$ is almost identical with that of 2 [29], which indicates that the introduction of the tert-butyl group does not significantly affect the bandgap energy of 1 compared with that of 2. As shown in Figure 3, dual emission is well resolved in the steady-state measurement of $\mathbf{1}$, which is composed of a normal emission band (enol form), justified by its mirror image with respect to the lowest lying absorption, and a large Stokes shifted $\left(5834 \mathrm{~cm}^{-1}\right)$ emission band maximized at 457 and $574 \mathrm{~nm}$, respectively. Accordingly, the assignment of a $574 \mathrm{~nm}$ emission for $\mathbf{1}$ in cyclohexane to a proton-transfer tautomer emission is unambiguous, and ESIPT takes place from the phenolic proton $(\mathrm{O}(1)-\mathrm{H})$ to the $\mathrm{O}(2)$ oxygen, forming the keto-tautomer species depicted in
Figure 4. Incidentally, the dual emission achieves a nearly white-light generation with $\operatorname{CIE}(0.28,0.26)$. The overall quantum yield of $\mathbf{1}$ is measured to be 0.07 and is about three times larger than that of $\mathbf{2}$, which can be explained by the fact that the bulky tert-butyl group reduces the intermolecular $\pi$ $\pi$ stacking of $\mathbf{1}$ so that the quantum yield can be improved.

3.5. Quantum Chemistry Computation. The optimized geometric structures and the corresponding hydrogen bond lengths of enol and keto form for $\mathbf{1}$ in the ground and the first singlet excited state were calculated using DFT and TD-DFT with the B3LYP functional and the $6-31 \mathrm{G}^{* *}$ basis set (Figure 4). From $\mathrm{E}\left(\mathrm{K}^{*}\right)$ to $\mathrm{E}^{*}(\mathrm{~K})$, we can see that the intramolecular hydrogen bond length decreases from 1.99 (1.81) $\AA$ to 1.89 (1.75) $\AA$, whereas the other bond lengths do not change. The results clearly provide the evidence for the strengthening of the intramolecular hydrogen bond from 

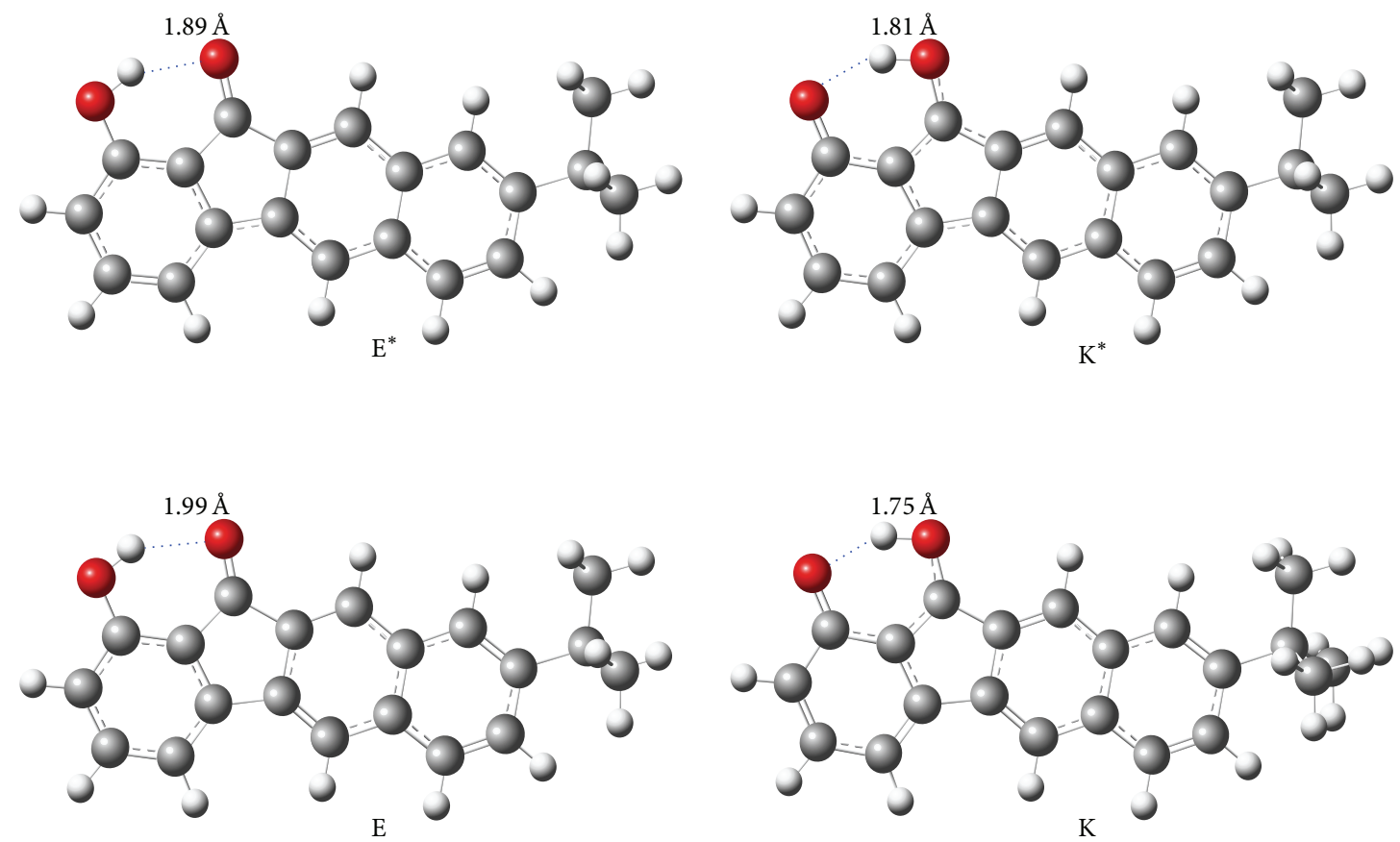

Figure 4: The optimized geometric structures of enol (E) and keto (K) form for $\mathbf{1}$ in the ground and the first singlet excited state together with the intramolecular hydrogen bond lengths.

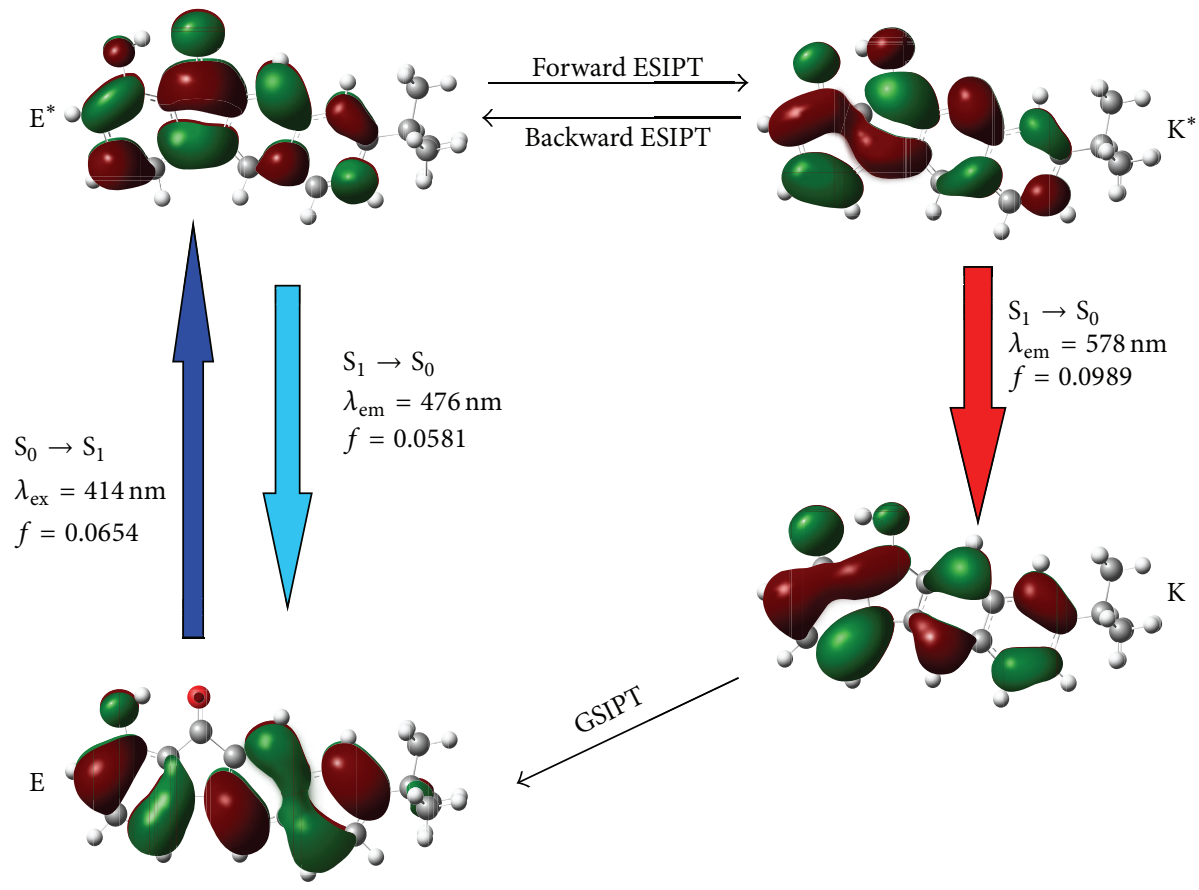

Figure 5: The frontier molecular orbitals of $\mathbf{1}$ for $\mathrm{E}, \mathrm{E}^{*}, \mathrm{~K}$, and $\mathrm{K}^{*}$. 
TABLE 2: Calculated and experimental parameters for $\mathbf{1}$.

\begin{tabular}{|c|c|c|c|c|c|c|c|c|c|}
\hline Compound & $\lambda_{\mathrm{abs}}{ }^{\mathrm{a}}$ & $\lambda_{\mathrm{em}}{ }^{\mathrm{a}}$ & $\Phi^{\mathrm{b}}$ & $E_{g}{ }^{\mathrm{c}}$ & $E(1)^{\mathrm{d}}$ & $E(-1)^{\mathrm{d}}$ & $E_{\mathrm{HOMO}} / E_{\mathrm{LUMO}}{ }^{\mathrm{e}}$ & $E_{\mathrm{HOMO}} / E_{\mathrm{LUMO}}{ }^{\mathrm{f}}$ & $E_{g}^{g}$ \\
\hline 1 & 430 & 457,574 & 0.07 & 2.88 & 1.34 & -1.28 & $-5.96 /-3.08$ & $-5.88 /-2.25$ & 2.99 \\
\hline \multicolumn{10}{|c|}{${ }^{\mathrm{a}}$ Measured in cyclohexane (in $\mathrm{nm}$ ). } \\
\hline \multirow{2}{*}{\multicolumn{10}{|c|}{$\begin{array}{l}\text { b Determined with } 2 \text { as [29]. } \\
{ }^{c} \text { At absorption maxima }\left(E_{g}=1240 / \lambda_{\max }, \text { in } \mathrm{eV}\right) \text {. }\end{array}$}} \\
\hline & & & & & & & & & \\
\hline \multicolumn{10}{|c|}{$\begin{array}{l}{ }^{\mathrm{d}} \text { Measured in a solution of } 0.1 \mathrm{M} \text { tetrabutylammonium hexafluorophosphate }\left(\mathrm{TBAPF}_{6}\right) \text { in dichloromethane versus SCE (in V). } \\
{ }^{\mathrm{e}} \text { Calculated from } E_{\mathrm{HOMO}}=-4.88-\left(E_{\mathrm{oxd}}-E_{\mathrm{Fc} / \mathrm{Fc}+}\right) \text { and } E_{\mathrm{LUMO}}=E_{\mathrm{HOMO}}+E_{g}(\mathrm{in} \mathrm{eV}) \text {. }\end{array}$} \\
\hline \multicolumn{10}{|c|}{${ }^{\mathrm{f}}$ Calculated by DFT/B3LYP (in eV). } \\
\hline
\end{tabular}

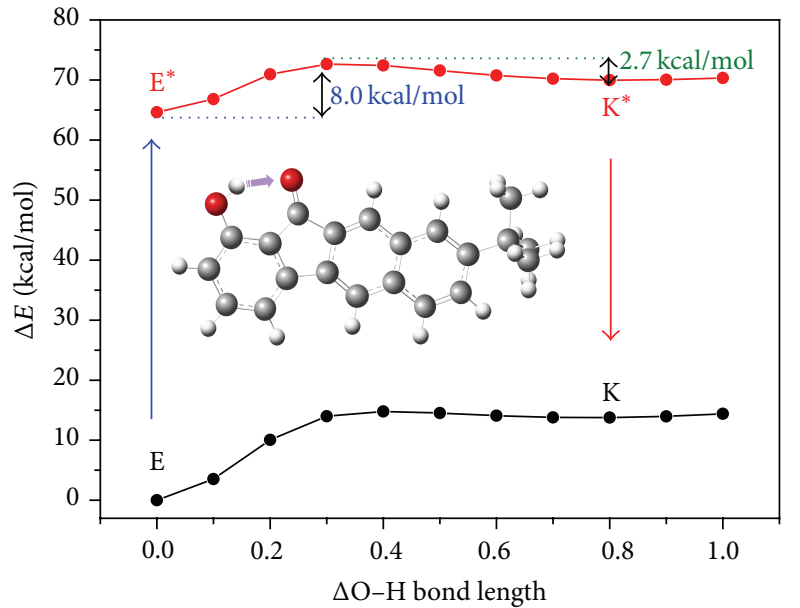

Figure 6: Potential energy curves (PECs) from enol form (E) to keto form $(\mathrm{K})$ of $\mathbf{1}$ at the ground state and excited state. The calculations are based on the optimized ground state geometry $\left(\mathrm{S}_{0}\right.$ state $)$ at the B3LYP/6-31G**/level using Gaussian 03W.

$\mathrm{S}_{0} \rightarrow \mathrm{S}_{1}\left(\mathrm{~S}_{1} \rightarrow \mathrm{S}_{0}\right)$, which is consistent with previous studies [38]. Therefore, there is no doubt that the decrease of intramolecular hydrogen bond lengths from $\mathrm{E}\left(\mathrm{K}^{*}\right)$ to $\mathrm{E}^{*}$ $(\mathrm{K})$ is a very important positive factor for the ESIPT (GSIPT: ground state intramolecular proton transfer) reaction.

Figure 5 shows the highest occupied molecular orbitals (HOMOs) and the lowest unoccupied molecular orbitals (LUMOs) of enol and keto form of $\mathbf{1}$, both of which are strongly delocalized over the entire $\pi$-conjugated system. It also reveals that the electron density around the intramolecular hydrogen binding site is mainly populated at hydroxyl oxygen and carbonyl oxygen at HOMO and LUMO, respectively. The results clearly demonstrate that, upon electronic excitation of $\mathbf{1}$, the hydroxyl proton $(\mathrm{O}(1)-\mathrm{H})$ is expected to be more acidic, whereas the carbonyl oxygen $\mathrm{O}(2)$ is more basic with respect to their ground state, driving the proton transfer reaction (forward ESIPT). After the forward ESIPT $\left(\mathrm{E}^{*} \rightarrow \mathrm{K}^{*}\right)$, the electron density located on $\mathrm{O}(1)$ increases while that on $\mathrm{O}(2)$ decreases, which shows the conspicuous intramolecular charge transfer from $\mathrm{O}(2)$ to $\mathrm{O}(1)$. This may supply the driving force for the proton transfer from $\mathrm{O}(2)$ to $\mathrm{O}(1)$ (backward ESIPT), so that the excitedstate equilibrium can be created. Moreover, the absorption and emission spectra of $\mathbf{1}$ were calculated by time-dependent

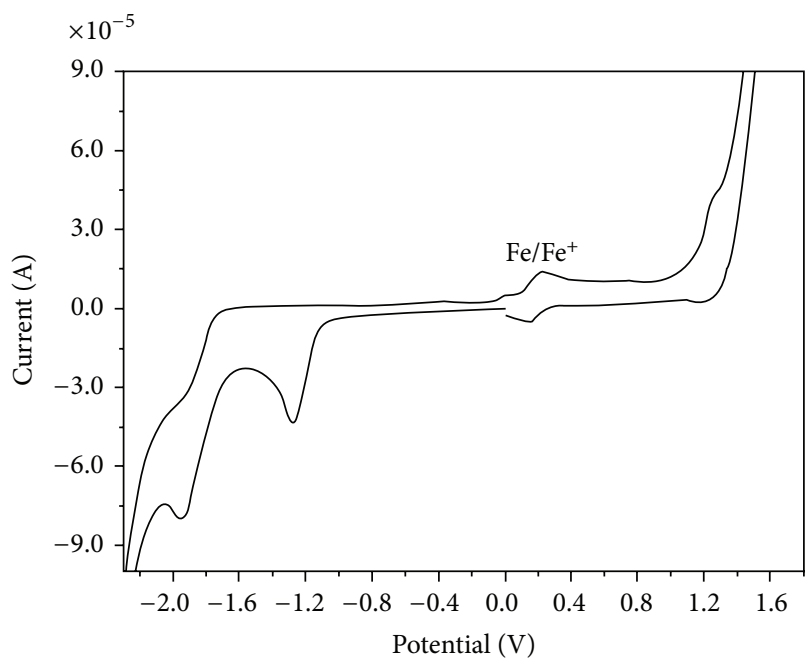

FIgURE 7: The cyclic voltammogram of 1 measured in dichloromethane solution with ferrocenium/ferrocene, at $200 \mathrm{mV} / \mathrm{s}$.

DFT calculations (Franck-Condon principle, Figure 5). The calculated excitation, normal emission, and tautomer emission wavelengths for the $\mathrm{S}_{0} \rightarrow \mathrm{S}_{1}\left(\mathrm{~S}_{1} \rightarrow \mathrm{S}_{0}\right)$ transitions are $414 \mathrm{~nm}, 476 \mathrm{~nm}$, and $578 \mathrm{~nm}$, respectively, which is very close to the experimental results (Table 2).

The potential energy curves of $\mathbf{1}$ as a function of the $\mathrm{O}(1)-$ $\mathrm{H}$ bond length were also studied (Figure 6). On the one hand, the full geometry optimization based on the B3LYP/6-31G ${ }^{* *}$ theoretical level reveals that the normal form (E) of $\mathbf{1}$ in the ground state is more stable than the corresponding protontransfer tautomer $(\mathrm{K})$ by $13.7 \mathrm{kcal} / \mathrm{mol}$. As a result, proton transfer from $\mathrm{K}$ to $\mathrm{E}$ is populated in the ground states. On the other hand (for the first singlet excited state), one can clearly see that the potential energy barriers of the forward $(8.0 \mathrm{kcal} / \mathrm{mol})$ and the backward $(2.7 \mathrm{kcal} / \mathrm{mol})$ ESIPT are in the same order of magnitude, which is in good agreement with previous theoretical results of 2 [38]. Accordingly, the forward and the backward ESIPT may happen on the same timescale and consequently leads to the rapidly established excited-state equilibrium.

3.6. Electrochemical Properties. The cyclic voltammogram of 1 is illustrated in Figure 7. When placed in dichloromethane and subjected to modest potentials, compound $\mathbf{1}$ shows one oxidation and two reduction waves that all are chemically 
irreversible. The first oxidation and reduction potentials of $\mathbf{1}$ are nearly identical to those of $\mathbf{2}$ [29], showing that the alkylation of $\mathbf{2}$ has no significant impact on both their electrochemical properties and their optical properties. Table 2 summarizes the redox potentials and the HOMO and LUMO energy levels estimated from cyclic voltammetry (CV) for 1 [39]. The HOMO/LUMO energy levels of 1 are estimated to be $-5.96 /-3.08 \mathrm{eV}$ and are in good agreement with the theoretical calculations.

\section{Conclusions}

In conclusion, we have successfully synthesized a new ESIPTbased white-light-emitting small molecule (1). Compound 1 undergoes an intramolecular proton transfer reaction in the excited state, resulting in a tautomer that is in equilibrium with the normal species, exhibiting a dual emission that generates white light. Analysis of the geometric structures clearly indicates that the intramolecular hydrogen bond length is shortened upon the photoexcitation, which is regarded as a very important factor for ESIPT. Furthermore, the potential energy curves suggest that the forward ESIPT and backward ESIPT may happen on the same timescale and leads to the rapidly established excited-state equilibrium. Research on its application to single-molecule-based white-light-emitting OLEDs is currently in progress.

\section{Conflict of Interests}

The authors declare no competing financial interests regarding the publication of this paper.

\section{Acknowledgment}

Financial support from the National Science Council of China is gratefully acknowledged (NSC 101-2113-M-035-001MY2).

\section{References}

[1] J. Zhao, S. Ji, Y. Chen, H. Guo, and P. Yang, "Excited state intramolecular proton transfer (ESIPT): from principal photophysics to the development of new chromophores and applications in fluorescent molecular probes and luminescent materials," Physical Chemistry Chemical Physics, vol. 14, no. 25, pp. 8803-8817, 2012.

[2] M. A. Satam, R. K. Raut, R. D. Telore, and N. Sekar, "Fluorescent acid azo dyes from 3-(1,3-benzothiazol-2-yl)naphthalen-2-ol and comparison with 2-naphthol analogs," Dyes and Pigments, vol. 97, no. 1, pp. 32-42, 2013.

[3] L. Xie, Y. Chen, W. Wu, H. Guo, J. Zhao, and X. Yu, "Fluorescent coumarin derivatives with large stokes shift, dual emission and solid state luminescent properties: an experimental and theoretical study," Dyes and Pigments, vol. 92, no. 3, pp. 13611369, 2012.

[4] P. Yang, J. Zhao, W. Wu, X. Yu, and Y. Liu, "Accessing the long-lived triplet excited states in bodipy-conjugated 2-(2hydroxyphenyl) benzothiazole/benzoxazoles and applications as organic triplet photosensitizers for photooxidations," Journal of Organic Chemistry, vol. 77, no. 14, pp. 6166-6178, 2012.

[5] M. A. Satam, R. K. Raut, and N. Sekar, "Fluorescent azo disperse dyes from 3-(1,3-benzothiazol-2-yl)naphthalen-2-ol and comparison with 2-naphthol analogs," Dyes and Pigments, vol. 96, no. 1, pp. 92-103, 2013.

[6] Z. Q. Guo, W. Q. Chen, and X. M. Duan, "Seven-membered ring excited-state intramolecular proton-transfer in 2-benzamido-3(pyridin-2-yl)acrylic acid," Dyes and Pigments, vol. 92, no. 1, pp. 619-625, 2011.

[7] J. E. Kwon, S. Park, and S. Y. Park, "Realizing molecular pixel system for full-color fluorescence reproduction: RGB-emitting molecular mixture free from energy transfer crosstalk," Journal of the American Chemical Society, vol. 135, no. 30, pp. 1123911246, 2013.

[8] M. H. Luo, H. Y. Tsai, H. Y. Lin, S. K. Fang, and K. Y. Chen, "Extensive spectral tuning of the proton transfer emission from green to red via a rational derivatization of salicylideneaniline," Chinese Chemical Letters, vol. 23, no. 11, pp. 1279-1282, 2012.

[9] T. C. Fang, H. Y. Tsai, M. H. Luo, C. Chang, and K. Chen, "Excited-state charge coupled proton transfer reaction via the dipolar functionality of salicylideneaniline," Chinese Chemical Letters, vol. 24, no. 2, pp. 145-148, 2013.

[10] A. U. Khan and M. Kasha, "Mechanism of four-level laser action in solution excimer and excited-state proton-transfer cases," Proceedings of the National Academy of Sciences of the United States of America, vol. 80, no. 6, pp. 1767-1770, 1983.

[11] W. H. Chen and Y. Pang, "Excited-state intramolecular proton transfer in 2-(2',6'-dihydroxyphenyl)benzoxazole: effect of dual hydrogen bonding on the optical properties," Tetrahedron Letters, vol. 51, no. 14, pp. 1914-1918, 2010.

[12] G. O. W. Lins, L. F. Campo, F. S. Rodembusch, and V. Stefani, "Novel ESIPT fluorescent benzazolyl-4-quinolones: synthesis, spectroscopic characterization and photophysical properties," Dyes and Pigments, vol. 84, no. 1, pp. 114-120, 2010.

[13] C. K. Lim, J. Seo, S. Kim, I. C. Kwon, C. Ahn, and S. Y. Park, "Concentration and $\mathrm{pH}$-modulated dual fluorescence in selfassembled nanoparticles of phototautomerizable biopolymeric amphiphile," Dyes and Pigments, vol. 90, no. 3, pp. 284-289, 2011.

[14] C. M. Maupin, N. Castillo, S. Taraphder et al., "Chemical rescue of enzymes: proton transfer in mutants of human carbonic anhydrase II," Journal of the American Chemical Society, vol. 133, no. 16, pp. 6223-6234, 2011.

[15] Y. Ito, K. Amimoto, and T. Kawato, "Prototropic tautomerism and solid-state photochromism of N-phenyl-2aminotropones," Dyes and Pigments, vol. 89, no. 3, pp. 319-323, 2011.

[16] R. C. D. Santos, N. V. D. S. Faleiro, L. F. Campo et al., "Synthesis and photophysical properties of novel succinimidyl benzazole derivatives, evaluated by Candida albicans ATCC 10231 fluorescent staining," Tetrahedron Letters, vol. 52, no. 23, pp. 3048-3053, 2011.

[17] T. Li, Z. Yang, Y. Li, Z. Liu, G. Qi, and B. Wang, "A novel fluorescein derivative as a colorimetric chemosensor for detecting copper(II) ion," Dyes and Pigments, vol. 88, no. 1, pp. 103-108, 2011.

[18] Y. J. Zhang, X. P. He, M. Hu, Z. Li, X. Shi, and G. Chen, "Highly optically selective and electrochemically active chemosensor for copper (II) based on triazole-linked glucosyl anthraquinone," Dyes and Pigments, vol. 88, no. 3, pp. 391-395, 2011. 
[19] W. H. Hong, C. C. Lin, T. S. Hsieh, and C. Chang, "Preparation of fluoroionophores based on diamine-salicylaldehyde derivatives," Dyes and Pigments, vol. 94, no. 3, pp. 371-379, 2012.

[20] Q. Huang, X. F. Yang, and H. Li, "A ratiometric fluorescent probe for hydrogen sulfide based on an excited-state intramolecular proton transfer mechanism," Dyes and Pigments, vol. 99, no. 3, pp. 871-877, 2013.

[21] S. Ikeda, M. Toganoh, S. Easwaramoorthi, J. M. Lim, D. Kim, and H. Furuta, "Synthesis and photophysical properties of Nfused tetraphenylporphyrin derivatives: near-infrared organic dye of [18] annulenic compounds," Journal of Organic Chemistry, vol. 75, no. 24, pp. 8637-8649, 2010.

[22] M. Ashraf, A. Teshome, A. J. Kay et al., "Synthesis and optical properties of NLO chromophores containing an indoline donor and azo linker," Dyes and Pigments, vol. 95, no. 3, pp. 455-464, 2012.

[23] J. E. Kwon and S. Y. Park, "Advanced organic optoelectronic materials: harnessing excited-state intramolecular proton transfer (ESIPT) process," Advanced Materials, vol. 23, no. 32, pp. 3615-3642, 2011.

[24] S. Park, J. Seo, S. H. Kim, and S. Y. Park, “Tetraphenylimidazolebased excited-state intramolecular proton-transfer molecules for highly efficient blue electroluminescence," Advanced Functional Materials, vol. 18, no. 5, pp. 726-731, 2008.

[25] W. T. Chuang, C. C. Hsieh, C. H. Lai et al., "Excited-state intramolecular proton transfer molecules bearing $o$-hydroxy analogues of green fluorescent protein chromophore," Journal of Organic Chemistry, vol. 76, no. 20, pp. 8189-8202, 2011.

[26] M. Mazzeo, V. Vitale, F. Della Sala et al., "Bright white organic light-emitting devices from a single active molecular material," Advanced Materials, vol. 17, no. 1, pp. 34-39, 2005.

[27] Y. Liu, M. Nishiura, Y. Wang, and Z. Hou, " $\pi$-conjugated aromatic enynes as a single-emitting component for white electroluminescence," Journal of the American Chemical Society, vol. 128, no. 17, pp. 5592-5593, 2006.

[28] S. Park, E. K. Ji, H. K. Se et al., "A white-light-emitting molecule: frustrated energy transfer between constituent emitting centers," Journal of the American Chemical Society, vol. 131, no. 39, pp. 14043-14049, 2009.

[29] K. C. Tang, M. J. Chang, T. Y. Lin et al., "Fine tuning the energetics of excited-state intramolecular proton transfer (ESIPT): white light generation in a single ESIPT system," Journal of the American Chemical Society, vol. 133, no. 44, pp. 17738-17745, 2011.

[30] S. Kim, J. Seo, H. K. Jung, J. Kim, and S. Y. Park, "White luminescence from polymer thin films containing excited-state intramolecular proton-transfer dyes," Advanced Materials, vol. 17, no. 17, pp. 2077-2082, 2005.

[31] G. M. Sheldrick, SHELXS97, a Program for Automatic Solution of Crystal Structure, University of Göttingen, Göttingen, Germany, 1997.

[32] G. M. Sheldrick, SHELX97, a Program for Crystal Structure Refinement, University of Göttingen, Göttingen, Germany, 1997.

[33] M. J. Frisch, G. W. Trucks, H. B. Schlegel et al., Gaussian 03, Gaussian, Inc., Pittsburgh, Pa, USA, 2003.

[34] M. Koné, B. Illien, J. Graton, and C. Laurence, "B3LYP and MP2 calculations of the enthalpies of hydrogen-bonded complexes of methanol with neutral bases and anions: comparison with experimental data," Journal of Physical Chemistry A, vol. 109, no. 51, pp. 11907-11913, 2005.
[35] T. Schaefer, "A relationship between hydroxyl proton chemical shifts and torsional frequencies in some ortho-substituted phenol derivatives," Journal of Physical Chemistry, vol. 79, no. 17, pp. 1888-1890, 1975.

[36] K.-Y. Chen, Y.-M. Cheng, C.-H. Lai et al., "Ortho green fluorescence protein synthetic chromophore; excited-state intramolecular proton transfer via a seven-membered-ring hydrogenbonding system," Journal of the American Chemical Society, vol. 129, no. 15, pp. 4534-4535, 2007.

[37] K.-Y. Chen, C.-C. Hsieh, Y.-M. Cheng, C. Lai, and P. Chou, "Extensive spectral tuning of the proton transfer emission from 550 to $675 \mathrm{~nm}$ via a rational derivatization of 10 hydroxybenzo[ $h]$ quinoline," Chemical Communications, no. 42, pp. 4395-4397, 2006.

[38] M. Zhang, D. Yang, B. Ren, and D. Wang, "A TDDFT study on the excited-state intramolecular proton transfer (ESIPT): excited-state equilibrium induced by electron density swing," Journal of Fluorescence, vol. 23, no. 4, pp. 761-766, 2013.

[39] H.-Y. Tsai and K.-Y. Chen, "1,7-Diaminoperylene bisimides: synthesis, optical and electrochemical properties," Dyes and Pigments, vol. 96, no. 2, pp. 319-327, 2013. 

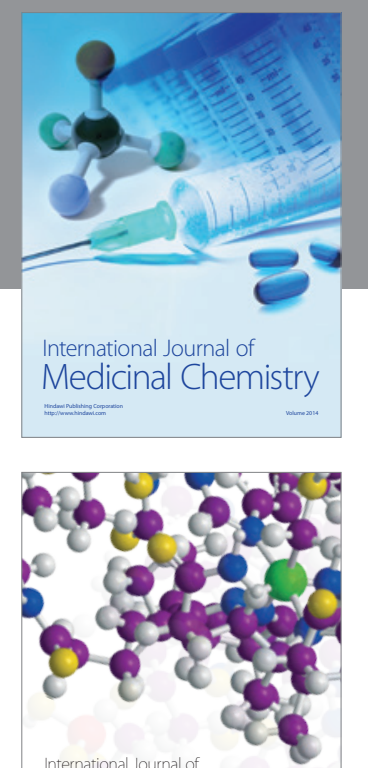

\section{Carbohydrate} Chemistry

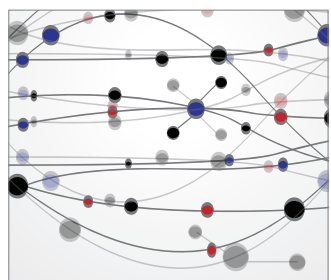

The Scientific World Journal
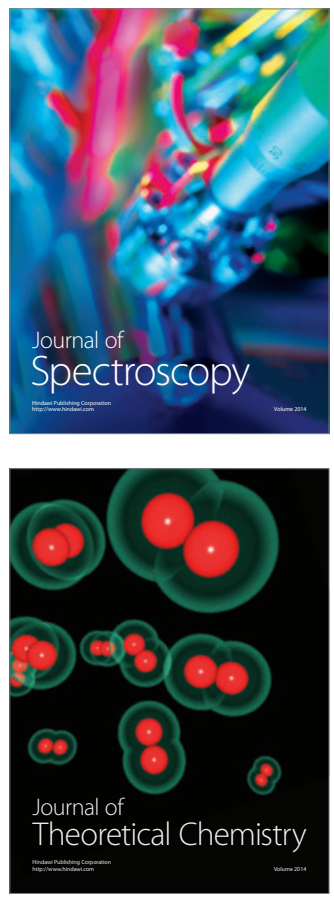
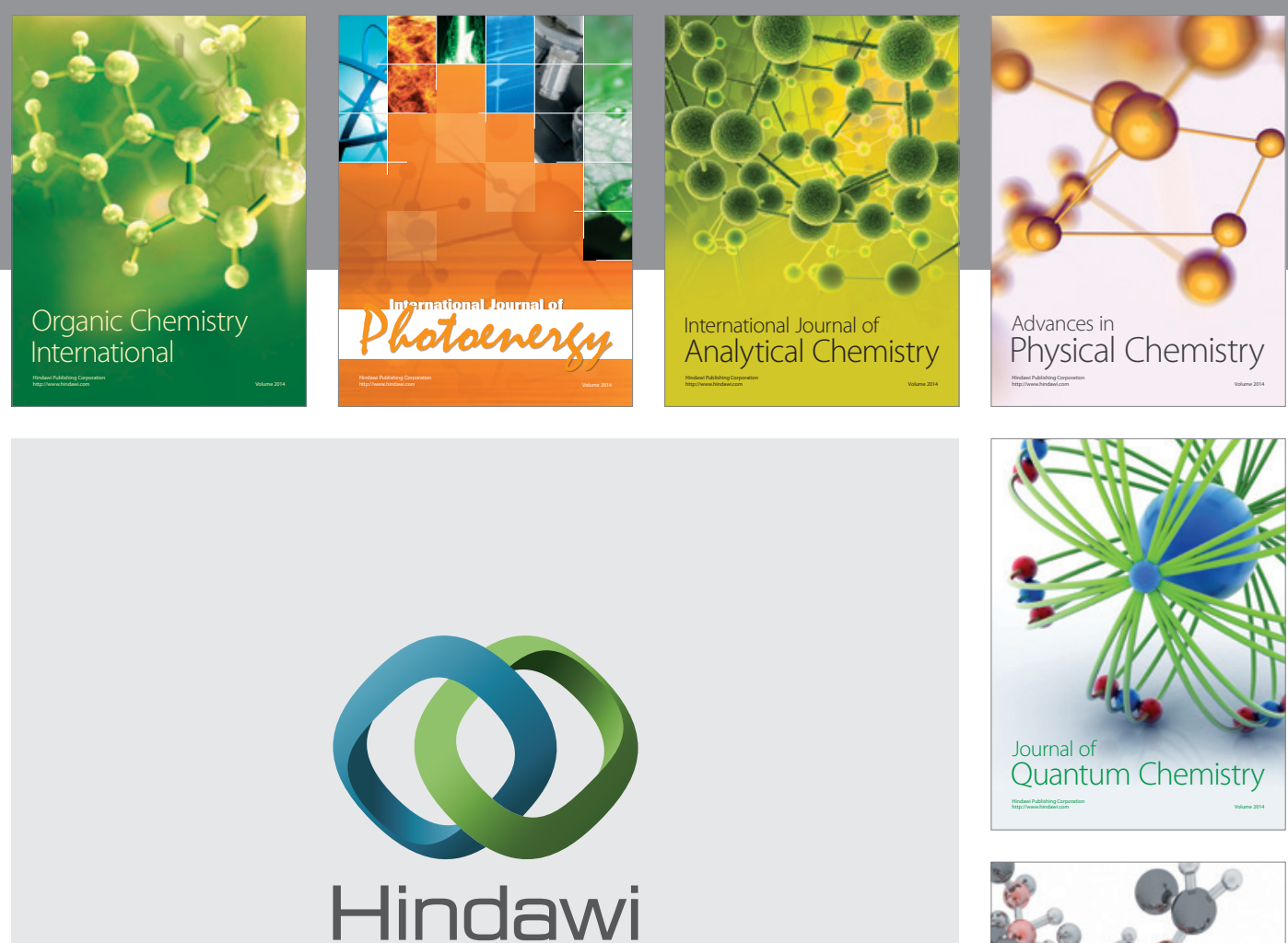

Submit your manuscripts at

http://www.hindawi.com

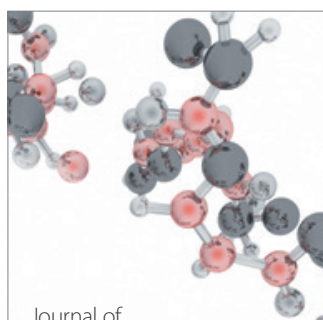

Analytical Methods

in Chemistry

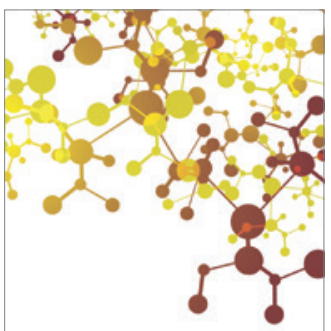

Journal of

Applied Chemistry

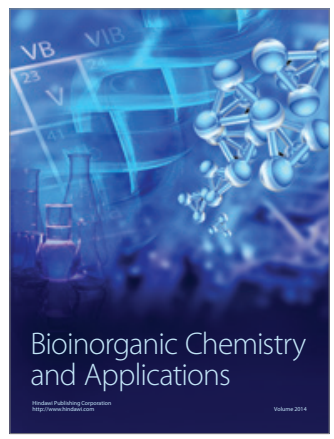

Inorganic Chemistry
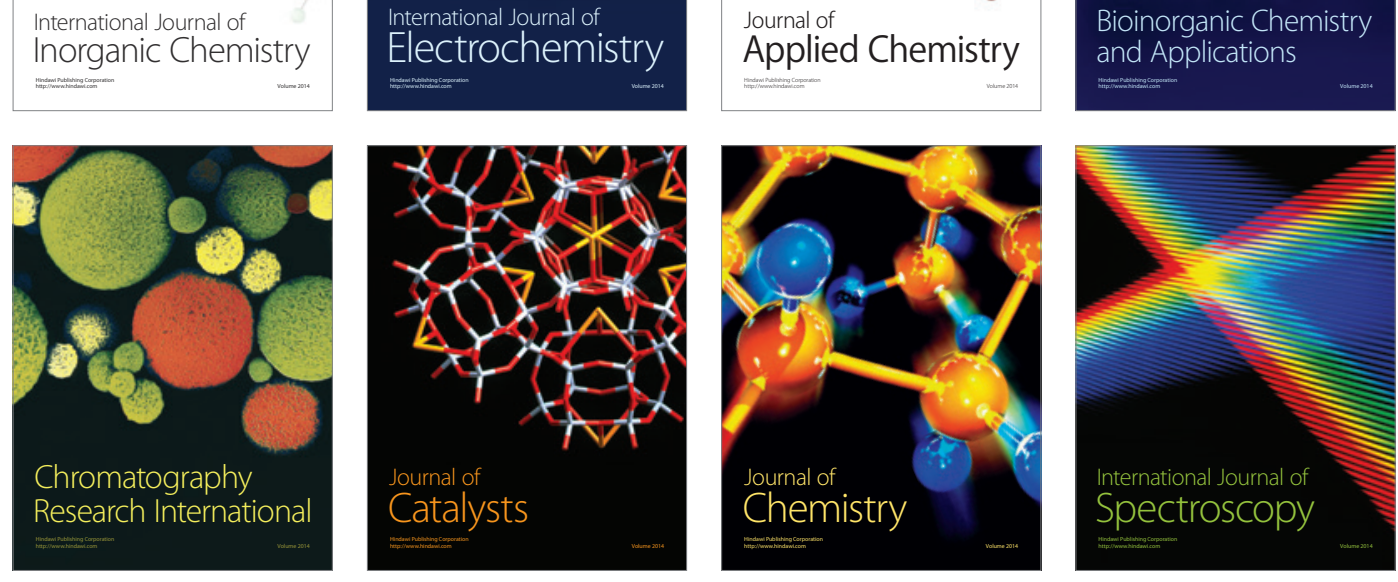